\title{
Flavonoids from Plant Source as Protein Tyrosine Phosphatase 1B Inhibitors: In Silico Update
}

Ihab ALMASRI ${ }^{1}$, Halima OTHMAN² ${ }^{2}$ Bashaer ABU-IRMAILEH ${ }^{3}$, Mohammad MOHAM$\mathrm{MAD}^{4}$, Yasser BUSTANJI5

1 Department of Pharmaceutical Chemistry and Pharmacognosy, Faculty of Pharmacy, Al Azhar University-Gaza, Gaza Strip, Palestine. https://orcid.org/0000-0001-5988-9 5059.

2 Department of Biological Sciences, University of Jordan, Amman, Jordan.

3 Hamdi Mango Center for Scientific Research, The University of Jordan, Amman.

4 Department of Pharmaceutical Sciences, Faculty of Pharmacy, The

University of Jordan.

5 Department of Basic Medical Sciences, College of Medicine, University of Sharjah, Sharjah 27272, UAE.

\begin{abstract}
Protein Tyrosine Phosphatase 1B (PTP1B) enzyme, type 1 non-transmembrane protein tyrosine phosphatase, is extensively expressed in different organs in the body and is linked to different signal transduction pathways including insulin signaling pathway. PTP1B inhibition exhibits significant effects on glucose homeostasis and glucose balance in blood and tissue. Several types of synthetic/natural compounds have been tested. Among these compounds, flavonoids showed high potency as PTP1B inhibitors. Different studies revealed that flavonoids could be promising PTP1B inhibitors with antidiabetic and weight loss effects. In recent years, the discovery of new flavonoids with PTP1B inhibition activity has been facilitated by the application of molecular modeling and computational methods. This review highlights the research efforts conducted in the discovery of flavonoids as PTP1B inhibitors and the role of computer-aided drug design techniques utilized in the discovery process.
\end{abstract}

Keywords: PTP1B, flavonoids, inhibitory activity, In Silico, diabetes mellitus

\footnotetext{
${ }^{*}$ Corresponding Author:

Ihab Almasri, Mobile: +970 599403 757; E-mail: ihabalmasri@yahoo.com

ORCIDs:

Ihab Almasri : :https://orcid.org/0000-0001-5988-9 5059.

Halima Othman : : https://orcid.org/0000-0001-5690-5317

Bashaer Abu-Irmaileh : : https://orcid.org/0000-0003-1040-3156

Mohammad Mohammad : https://orcid.org/0000-0003-0025-365X

Yasser Bustanji : : https://orcid.org/0000-0003-1315-0609

(Received 07 February 2021, Accepted 7 June 2021)
} 


\section{INTRODUCTION}

For several millenniums, products derived from nature were considered a keystone in human strategies against diseases as a treatment and preventive agents. Recently, the interest in using medicinal plants for the treatment of diseases in many countries has increased. Natural products have wide structural and chemical diversity which continue to motivate novel discoveries in medicine. However, besides their biological and chemical diversity, the emergence of innovative technologies has reformed the screening of natural products methods used in discovering new drugs. They are evolutionarily optimized as drug-like molecules, and have therefore proved to be an important source for new drugs and bioactive leads. About 35\% of approved drugs over the past two decades were plant based or derived from natural sources ${ }^{1,2}$. The discovery of novel, safer and more efficacious medicines continues to be the most significant goal regarding the development of new drugs. Therefore, researchers have recently reconsidered the use of bioactive compounds obtained from natural sources in folk medicine to treat diabetes mellitus (DM), cancer, and other diseases because of their natural origination ${ }^{3}$.

Protein tyrosine phosphatase 1B (PTP1B)is an ubiquitously expressed phosphatase that has emerged as a relevant regulator of a variety of signaling pathways initiated by the activation of the tyrosine kinase receptor superfamily ${ }^{4}$. Therefore, several potential therapeutic uses of PTP1B inhibitors were reported in the literature. It was disclosed that increased PTP1B activity is associated with defective neuronal insulin signaling pathways that are impaired in Alzheimer's disease (AD), therefore PTP1B inhibition may represent an interesting therapeutic approach to modify abnormal signaling processes linked to $\mathrm{AD}^{4}$. Moreover, it was found that the expression of PTP1B is increased in inflammatory conditions where it plays a role in neuroinflammation ${ }^{5}$. PTP1B also acts as a negative regulator of interleukin-4-induced anti-inflammatory signaling, and thus it is considered a potential therapeutic target for neuroinflammatory and neurodegenerative diseases ${ }^{5}$. Additionally, $\mathrm{PTP} 1 \mathrm{~B}$ is an active player in several types of cancer including lung cancer and breast cancer, both as an oncogene and a tumor suppressor. The enzyme plays a role in the regulation of cell migration and adhesion in cancerous as well as normal cells ${ }^{6}$. Recently, PTP1B has received attention in liver diseases and represents an interesting target by modulating liver cells death, survival, and hepatic lipogenesis ${ }^{7}$. More notably is a decline in the number of apoptotic liver cells and the level of liver enzymes due to the interruption of PTP1B in mice model. Furthermore, PTP1B contributes to the cardiovascular disturbances at different molecular levels and 
therefore, PTP1B inhibitors could be used in prevention and reversal of atherosclerosis development and thus reduces cardiovascular disease risk $^{8}$.

PTP1B has been identified as a negative regulator of both insulin and leptin signaling pathways leading to decreased sensitivity to both hormones. Studies have shown that insulin resistant conditions are associated with increased expression and activity of $\mathrm{PTP} 1 \mathrm{~B}$ and therefore is considered a valid therapeutic target for diabetes ${ }^{8,9}$. Diabetes mellitus type 2 (T2DM) is a chronic metabolic disorder manifested by high levels of blood sugar associated with a gradual decrease in insulin secretion and/or increase of insulin resistance. T2DM accounts for $90 \%$ of the cases of diabetes globally and about $90 \%$ of adults with T2DM are overweight or obese ${ }^{10,11}$. Therefore, it is not unexpected that substantial efforts have been made to identify medicines to treat T2DM. Several animal models, cell lines and clinical studies have shown that deficiency of PTP1B activity is accompanied by resistance to obesity with an increase in insulin sensitivity ${ }^{8,9}$.

The significance of such target has increased the demand of substantial research in the discovery of PTP1B inhibitors for T2DM and obesity treatment ${ }^{9,12}$. Within the last few years, there has been a growing interest in the discovery of antidiabetic and weight loss agents from natural products. Among these natural products, flavonoids were found to be an important source for new antidiabetic drugs, whereas numerous cell and animal studies support the hypoglycemic activity of flavonoids including PTP1B inhibition ${ }^{13}$.

In this review, we will provide a brief overview of flavonoids as natural products with anti-PTP1B activity, including a discussion of the results of many recent studies focused on the discovery of flavonoids as PTP1B inhibitors using computer-aided drug discovery techniques.

\section{PTP1B structural biology and its mechanism as a target for obesity and diabetes}

Protein tyrosine phosphatases (PTPs), signaling enzymes, are a group of enzymes which catalyze the dephosphorylation of tyrosine phosphorylated proteins. PTPs have a considerable effect on regulation of a number of cellular operations such as proliferation and differentiation, growth, cell-cell adhesion, metabolism, cell matrix contacts, and immune response. In particular, PTP1B,also known as protein tyrosine phosphatase non-receptor type 1 , is a type 1 non-transmembrane protein that catalyzes tyrosine phosphorylated proteins. It is widely distributed indifferent organs in the human body and participated in different signal transduction pathways ${ }^{14}$. PTP1B participates 
in insulin signaling pathway by dephosphorylation of insulin receptor and its downstream signaling components, which involved in glucose level regulation and resulted in diabetes and weight gain or as called diabesity; obesity resulted from diabetes ${ }^{15,16}$. Accordingly, targeting the activity of this enzyme is suggested to have therapeutic effect in diabetes. PTP1B inhibitors are attractive leads for the treatment of insulin resistance in diabetes. The discovery of the crystal structure of human PTP1B and its catalytic site by Barford and colleagues helped in understanding, illustrating, predicting, and designing potent inhibitors (Figure 1$)^{17}$.

A

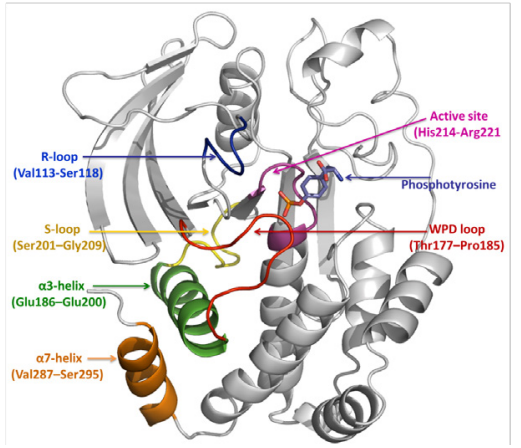

B

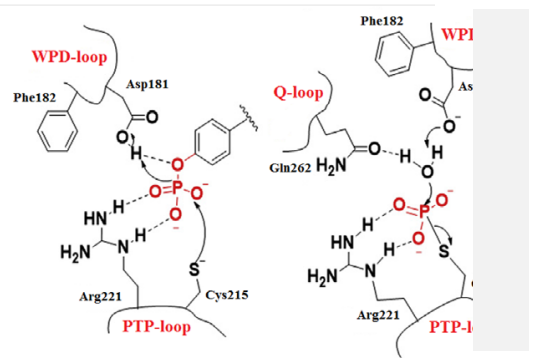

Figure 1: A. Cartoon representation of PTP1B protein structural elements18. B. The catalytic mechanism of tyrosine dephosphorylation within the active site.

The majority of PTP1B crystal structures consist of a single domain, arranged in eight $\alpha$ helices and eleven $\beta$ strands (Figure 1). The catalytic site of PTP1B composed of amino acid residues His214-Arg221 and loops R (Val113-Ser118),WPD (Thr177-Pro185). WPD-loop, conserved protein loop, contains three highly conserved residues: tryptophan (W), proline (P) and aspartic acid (D). The other main elements of PTP1B are: R3-helix (Glu186-Glu200); R6-helix (Ala264Ile281); and R7-helix (Val287-Ser295); and S loops (Ser201-Gly209) which play a role in the binding of substrate and take part in dephosphorylation of tyrosine moiety of substrate proteins ${ }^{18,19}$. Several X-ray crystallized structures revealed that Cys215, Arg22, Asp181, and Gln262 are the most vital residues in the enzyme catalytic activity ${ }^{20}$. Within the catalytic site Cys215 acts as a nucleophile in the primary separating phase. Moreover, a non-catalytic allosteric binding site for small molecule inhibitors was also identified (Figure 1) ${ }^{21}$. 
Selectivity is a very significant issue in the strategy of designing new PTP1B inhibitors. Targeting the catalytic active site of $\mathrm{PTP} 1 \mathrm{~B}$, which is highly conserved among PTPs, raised substantial challenges regarding the selectivity and bioavailability of the enzyme inhibitors due to the highly charged character of the binding site. Therefore, researchers were encouraged to explore other mechanisms of enzyme inactivation.

In 2004, a newPTP1B allosteric site nearby the active binding pocket (20 $\AA$ ) was discovered. It was revealed that allosteric inhibitors trap inactive conformation by inhibiting flexibility of the catalytic loop ${ }^{22}$. Moreover, Krishnan et al. (2014) have identified a new mechanism of allosteric inhibition throughout targeting the non-catalytic part of PTP1B at the C-terminal. It was demonstrated that targeting on-catalytic area adjacent to the active site would lock PTP1B in an inactive state as a result of the cooperative effects between the two sites ${ }^{23}$. Therefore, targeting the allosteric site would provide superior selectivity, less side effects, and lower toxicity because of its hydrophobic nature and no conserved sequence. Consequently, the allosteric site emerged as an interesting target in drug discovery.

\section{Regulation of insulin signaling pathway}

Insulin is a peptide hormone secreted by $\beta$-cell and is found to be negatively regulated by $\mathrm{PTP} 1 \mathrm{~B}$. Upon binding to the extracellular a subunits of its receptor, insulin receptor (IR) is activated by autophosphorylation. Subsequently, phosphorylation of Tyrosine residues of insulin receptor substrates (IRS) mostly recruits and activates the phosphoinositide 3-kinases (PI3K) leading to the generation of second messenger phosphatidylinositol-3,4,5-triphosphate (PIP3)(Figure 2) ${ }^{24,25}$. The membrane-bound PIP3 recruits and activates protein kinase-1 (PDK-1), which phosphorylates the protein kinase B (PKB). Pleckstrin homology (PH) domain, which is part of PDK-1, plays an important role in the activation of PDK-1 and the subsequent activation of Akt/PKB upon strong binding to membrane-bound PIP3. PDK-1 phosphorylates PKB/Akt at Thr308. Therewith, phosphorylation at Ser-473 is essential for complete activation of $\mathrm{PKB}$, and this is achieved by the mammalian target of rapamycin complex 2 $(\mathrm{mTORC} 2)^{23}$.

Activated $\mathrm{PKB} /$ Akt plays the main role in interceding insulin action and metabolic effects such as gluconeogenesis, glycogen synthesis, and glucose transport. The phosphorylation of the activated Akt substrate, AS160, is required for translocation of glucose transporter 4 (GLUT4) to the plasma membrane in a process known as GLUT4 translocation. PTP1B dephosphorylates the tyrosine residues on activated IR and IRS, thereby leading to their deactivation. The ac- 
tion of PTP1B resulted in impediment of the activation of $\mathrm{PI}_{3} \mathrm{~K}$ and $\mathrm{PKB} / \mathrm{Akt}$ and subsequent downstream kinases and therefore turns off insulin signal. As a result, GLUT4 translocation is inhibited and therefore cellular glucose uptake is reduced, and insulin resistance occurred, which reduces glucose intake and increased hepatic glucose output, which finally cause increment in blood glucose level (Figure 2) ${ }^{24,25}$.

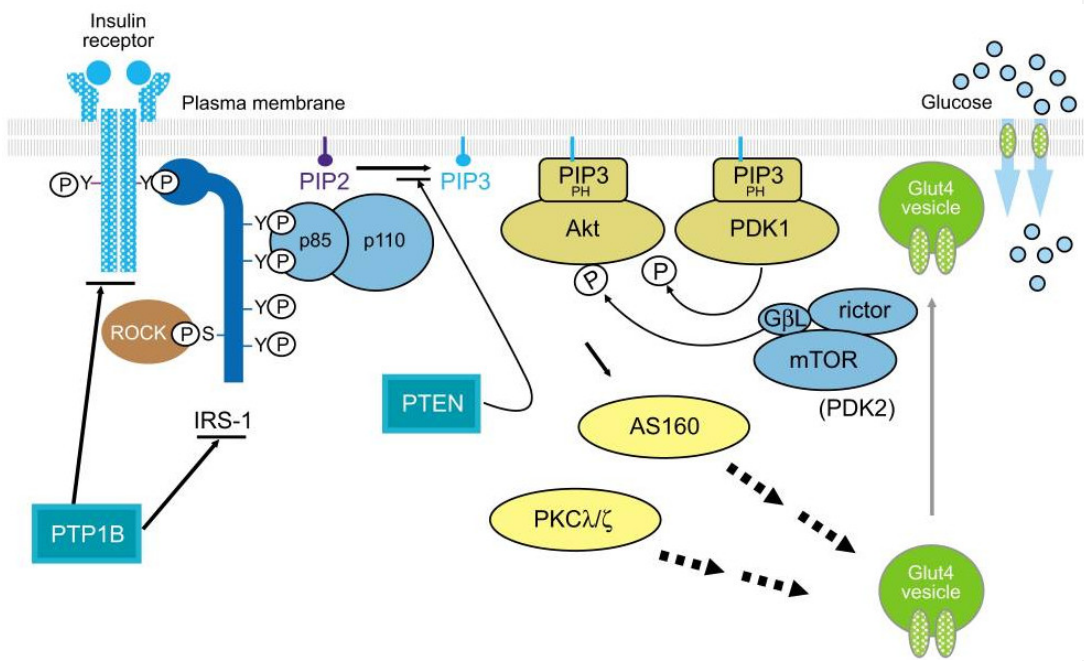

Figure 2: Negative regulation of insulin signaling pathway by PTP1B. Binding of insulin with its receptor tyrosine kinase (IR) results in the phosphorylation of insulin receptor substrates (IRS). Main IRS-mediated pathways include the PI3K/Akt pathway, which plays a central role in activation and regulation of several metabolic processes, including glycogen and protein synthesis glucose transport stimulation and adipogenesis. IR is dephosphorylated and inactivated by PTP1B which has negative effects on glucose metabolism and insulin action ${ }^{25}$.

\section{Flavonoids as PTP1B inhibitors}

Flavonoids belong to a class of secondary plant metabolites having polyphenolic structure that exist extensively in nature and in the human diet. They are composed of 15 carbon atoms, having two aromatic rings connected by three carbon atoms. Flavonoids have several subgroups, which include chalcones, flavonols, flavones, flavanones, isoflavones, catechins, and anthocyanidins (Figure 3). Their broad spectrum of biological activity such as antidiabetic, cardioprotective, antitumor, anti-inflammatory, antiviral, antioxidant and antiplatelet activities, has attracted great interest in research on flavonoids ${ }^{26}$. 

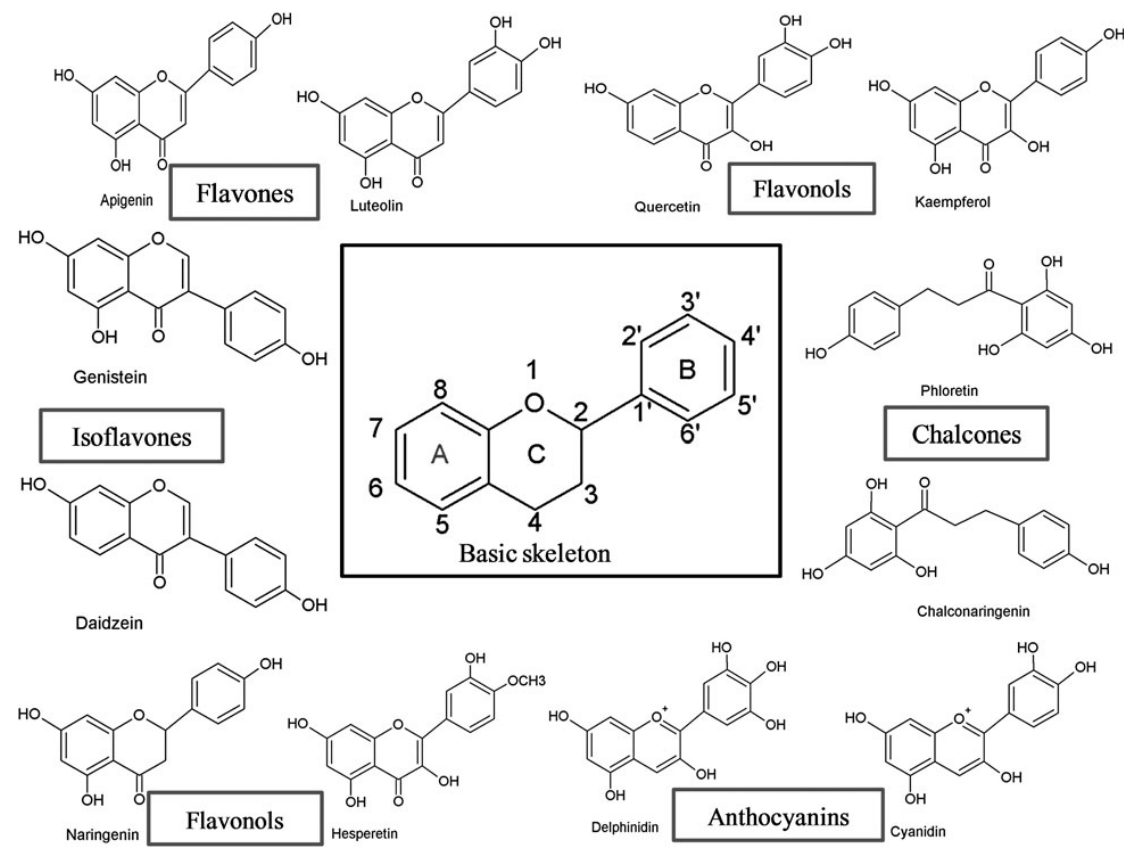

Figure 3: Basic skeleton structure of flavonoids and their classes ${ }^{26}$.

In 2002, Ueda and colleagues were the first to study a natural derived inhibitor for PTP1B. They isolated 4-Isoavenaciolide from a fungal strain and was identified as an inhibitor of PTP1B with $\mathrm{IC}_{50}$ of $10.7 \mu \mathrm{M}^{27}$.

The interest in exploring the bioactivity of Erythrina species has led to the separation of many biologically active compounds that inhibit PTP1B in vitro. A bioassay-guided fractionation of the ethanolic extract of the stem bark of $E$. addisoniae (Leguminosae) has resulted in the identification of a group of prenylated isoflavonoids regarded as $\mathrm{PTP} 1 \mathrm{~B}$ inhibitors ${ }^{28}$. Three of these natural molecules showed potential inhibition against $\mathrm{PTP} 1 \mathrm{~B}$ with $\mathrm{IC}_{50}$ values ranging between $2.6 \pm 0.5$ to $10.1 \pm 0.3 \mu \mathrm{M}$ (compounds 1-3, Figure 4). It was noticed that cyclization between a hydroxyl group at $\mathrm{C}-7$ and one of the prenyl groups at C-6 or C-8 in the ring $\mathbf{A}$ and the presence of hydroxyl group in ring $\mathbf{B}$ at positions 2'and 4' could be significant for activity ${ }^{28}$. Further exploration for this plant resulted in the separation of six2-arylbenzofuran derivatives from the stem bark. Three of them (4-6, Figure 4) were new with relatively strong in vitro anti-PTP1B activity $\left(\mathrm{IC}_{50} \text { between } 13.6 \pm 1.1 \text { to17.5 } \pm 1.2\right)^{29}$. Moreover, 12 flavanones with 2,2-dimethylpyrano ring were isolated, six of them (7-12, Figure 4) showed in vitro $\mathrm{PTP} 1 \mathrm{~B}$ inhibition with $\mathrm{IC}_{50}$ values ranging between 
$13.9 \pm 2.1$ and $19.0 \pm 1.8 \mu \mathrm{M}^{30}$. The obtained results showed that the presence of methoxy groups and prenyl moiety on ring $\mathbf{B}$ boost the PTP1B inhibitory activity of isolated flavanones.

Nguyen et al., reported the isolation of 15 pterocarpan derivatives and 6 prenylated isoflavonoids from the alcoholic extract of the root and the stem bark of $E$. abyssinica and E. addisoniae, respectively ${ }^{31,32}$. All the isolated compounds were evaluated for their PTP1B inhibition activity, as well as for their cytotoxic activities against a group of breast cancer cell lines. Pterocarpan derivatives (13-20, Figure 4) which have anti-PTP1B activity $\left(\mathrm{IC}_{50}\right)$ ranging from $4.2 \pm 0.2$ to $19.3 \pm 0.3 \mu \mathrm{M}$, displayed potential cytotoxic activities $\left(\mathrm{IC}_{50}\right.$ between $5.6 \pm$ 0.7 to $28.0 \pm 0.2 \mu \mathrm{M})$. Similarly, prenylated isoflavonoids (21-25, Figure 4) which have anti-PTP1B activity, between $4.6 \pm 0.3$ to $24.2 \pm 2.1 \mu \mathrm{M}$, exhibited strong cytotoxic activities $(3.97 \pm 0.17$ to $11.4 \pm 1.9 \mu \mathrm{M})$. Structurally similar isoflavonoids derivatives of another Erythrina species (E. lysistemon, Hutch) were separated from the stem bark. Nine of them showed in vitro potential inhibition of PTP1B and the most potent compound was 26 (Figure 4) with an $\mathrm{IC}_{50}=1.01 \pm 0.3 \mu \mathrm{g} / \mathrm{mL}(2.4 \mu \mathrm{M})^{33}$. The obtained results supported the previous remarks, regarding the structural activity relationship (SAR) of prenylated isoflavonoids ${ }^{28}$, which suggested that the presence of prenyl groups on pterocarpans could enhance their inhibitory activity especially at ring $\mathbf{A}$ and/or $\mathbf{D}$. Furthermore, the presence of an aldehyde at C-8 and a hydroxyl group at C-6 may account for the decrease in activity ${ }^{33}$.

A natural product library of 42 licorice flavonoids was screened against PTP1B. Several compounds with potential PTP1B inhibitory activity were identified, and the most potent compound was licoagrone $\left(27, \mathrm{IC}_{50}=6.0 \mu \mathrm{M} \text {, Figure } 5\right)^{34}$. Similarly, screening of another natural compounds library resulted in the discovery of five new inhibitors of PTP1B that were isolated from Sophora flavescens $^{35}$. These compounds were derivatives of lavandulyl flavonoids, and the most potent compound was 2'-methoxykurarinone $\left(\mathbf{2 8}, \mathrm{IC}_{50}=5.26 \pm 0.24 \mu \mathrm{M}\right.$, Figure 5), which is a noncompetitive PTP1B inhibitor $\left(K_{i}=3.15 \mu \mathrm{M}\right)^{35}$.

Luteolin (29, Figure 5), an abundant flavonoid existing in numerous vegetables and fruits, was reported to have potent $\mathrm{PTP} 1 \mathrm{~B}$ inhibitory activity $\left(\mathrm{IC}_{50}=6.70\right.$ $\pm 0.03 \mu \mathrm{M})$. However, isoorientin and orientin, two C-glycosylated luteolin derivatives, were both inactive at the same concentration, which points out that C-glycosylation at various positions on luteolin could have a negative influence on luteolin-PTP1B inhibitory activity ${ }^{36}$. 
Investigation of the extract of Cudrania tricuspidata roots led to the separation of 16 compounds. Four of the isolated compounds were flavonoids (30-33, Figure 5) that showed significant PTP1B inhibitory activity in a dose-dependent manner, with $\mathrm{IC}_{50}$ ranging from 5.7-13.6 $\mu \mathrm{M}$. Moreover, kinetic analyses revealed that the isolated flavonoid (32) was a noncompetitive PTP1B inhibitor, so it could be considered a valuable lead compound in designing antidiabetic and weight loss agents ${ }^{37}$.

In another study, nine natural products were separated from Ficus tikoua (Moraceae). Two of these compounds were novel isoprenylated flavanones, while seven of them showed moderate in vitro PTP1B inhibition activities IC $_{50}$ range from $11.16-40.37 \mu \mathrm{M})$. The most potent one was the isoflavone derivative with $\mathrm{IC}_{50}=11.16 \mu \mathrm{M}(\mathbf{3 4} \text {, Figure } 5)^{38}$.

Three isolated flavonoids from Agrimoni apilosa showed a good inhibitory potency against $\mathrm{PTP}_{1} \mathrm{~B}^{39}$. Kaempferol-3-O- $\mathrm{\alpha}$-L-rhamnoside (35) was the most potent flavonoid $(12.16 \pm 0.02 \mu \mathrm{M})$ while compound (36), apigenin-7- $O-\beta-\mathrm{D}$ glucuronide-6"-methyl ester, showed strong PTP1B inhibition $\left(\mathrm{IC}_{50}=14.35 \pm\right.$ $0.76 \mu \mathrm{M})$ (Figure 5).

In 2015, Jiang, et al., evaluated the pharmacological activity of several flavonoids derived from Hypericum scabrum L. and they found that only quercetin (37, Figure 5) exhibited significant PTP1B inhibitory activity $\left(\mathrm{IC}_{50}=2.19 \pm 0.2\right.$ $\mu \mathrm{M}$, Figure 5$)^{40}$.

Eight geranyl-substituted flavonoids with dual inhibition of $\alpha$-glucosidase and PTP1B were separated from the methanolic extract of the fruits of Paulownia tomentosa (38-45, Figure 5). All of them exhibited effective mixed type I PT$\mathrm{P} 1 \mathrm{~B}$ inhibition activity $\left(\mathrm{IC}_{50}\right.$ values between $1.9-8.2 \mu \mathrm{M}$ ) as shown by enzymatic kinetics study ${ }^{41}$.

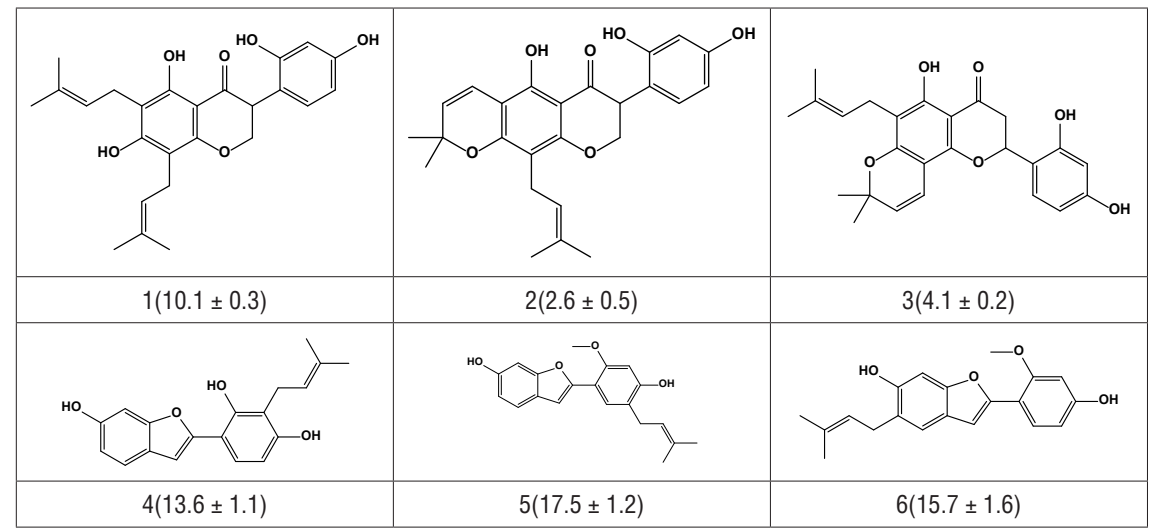




\begin{tabular}{|c|c|c|}
\hline (c) & $\left.\right|_{R_{1}} ^{R_{R_{2}}^{R_{2}^{2}}}$ & (n) \\
\hline $\begin{array}{c}7(13.9 \pm 2.1) \\
\left(\mathrm{R}_{1}=\text { prenyl, } \mathrm{R}_{2}=\mathrm{OH}, \mathrm{R}_{3}=\mathrm{CH}_{3}\right) \\
\quad 8(17.9 \pm 1.7) \\
\left(\mathrm{R}_{1}=\mathrm{H}, \mathrm{R}_{2}=\mathrm{OCH}_{3}, \mathrm{R}_{3}=\mathrm{CH}_{2} \mathrm{OH}\right)\end{array}$ & $\begin{array}{c}9(14.9 \pm 1.6) \\
\left(\mathrm{R}_{1}=\mathrm{R}_{5}=0 \mathrm{H}, \mathrm{R}_{2}=\mathrm{R}_{4}=\mathrm{H}, \mathrm{R}_{3}=\text { prenyl }\right) \\
10(18.2 \pm 2.1) \\
\left(\mathrm{R}_{1}=\mathrm{R}_{5}=0 \mathrm{OH}, \mathrm{R}_{2}=\mathrm{R}_{4}=\mathrm{H}, \mathrm{R}_{3}=\mathrm{CCH}_{3}\right) \\
11(19.0 \pm 1.8) \\
\left(\mathrm{R}_{1}=\mathrm{R}_{4}=\mathrm{R}_{5}=\mathrm{OH}, \mathrm{R}_{2}=\mathrm{H}, \mathrm{R}=\text { prenyl }\right) \\
12(18.2 \pm 1.2) \\
\left(\mathrm{R}_{1}=\mathrm{R}_{4}=\mathrm{R}_{5}=\mathrm{OH}, \mathrm{R}_{2}=\text { prenyl, } \mathrm{R}_{3}=\right. \\
\mathrm{OH})\end{array}$ & $\begin{array}{c}13(19.3 \pm 0.3) \\
\mathrm{R}_{1}=\mathrm{R}_{2}=\mathrm{R}_{4}=\mathrm{H}, \mathrm{R}_{3}=\mathrm{OCH}_{3}, \mathrm{R}_{5}=\mathrm{CH}_{3}, \\
\mathrm{R}_{6}=\text { prenyl } \\
14(19.5 \pm 1.5) \\
\mathrm{R}_{1}=\mathrm{R}_{3}=\mathrm{R}_{4}=\mathrm{R}_{5}=\mathrm{R}_{6}=\mathrm{H}, \mathrm{R}_{2}=\text { prenyl } \\
15(7.3 \pm 0.1) \\
\mathrm{R}_{1}=\mathrm{R}_{3}=\mathrm{R}_{5}=\mathrm{R}_{6}=\mathrm{H}, \mathrm{R}_{2}=\mathrm{R}_{4}=\text { prenyl } \\
26(2.4 \mu \mathrm{M}) \\
\mathrm{R}_{1}=\mathrm{R}_{3}=\mathrm{R}_{4}=\mathrm{R}_{5}=\mathrm{H}, \mathrm{R}_{2}=\mathrm{R}_{6}=\text { prenyl }\end{array}$ \\
\hline$R_{1}$ & 7 & \\
\hline $\begin{array}{c}16(4.2 \pm 0.2) \\
\mathrm{R}_{1}=\mathrm{R}_{3}=\mathrm{H}, \mathrm{R}_{2}=\text { prenyl } \\
17(7.8 \pm 0.5) \\
\mathrm{R}_{1}=\text { prenyl, } \mathrm{R}_{2}=\mathrm{R}_{3}=\mathrm{H} \\
18(8.8 \pm 0.5) \\
\mathrm{R}_{1}=\text { prenyl, } \mathrm{R}_{2}=\mathrm{H}, \mathrm{R}_{3}=\mathrm{OH}\end{array}$ & $19(7.6 \pm 0.9)$ & $20(6.4 \pm 0.6)$ \\
\hline (c) & $\mathrm{CH}_{3}$ & \\
\hline $\begin{array}{c}21(17.4 \pm 1.1) \\
\mathrm{R}_{1}=\mathrm{R}_{5}=\mathrm{H}, \mathrm{R}_{2}=\mathrm{R}_{3}=\text { prenyl, } \mathrm{R}_{4}=\mathrm{R}_{6}=\mathrm{OH} \\
22(7.8 \pm 0.5) \\
\mathrm{R}_{1}=\mathrm{R}_{2}=\mathrm{R}_{4}=\mathrm{H}, \mathrm{R}_{3}=\mathrm{R}_{5}=\text { prenyl, } \mathrm{R}_{6}=\mathrm{OH} \\
23(4.6 \pm 0.3) \\
{ }^{*} \mathrm{R}_{1}=\mathrm{OH}, \mathrm{R}_{2}=\mathrm{R}_{3}=\mathrm{R}_{4}=\mathrm{H}, \mathrm{R}_{5}=\text { prenyl, } \\
\mathrm{R}_{6}=\mathrm{OCH}_{3}\end{array}$ & $24(13.8 \pm 1.8)$ & $25(24.2 \pm 2.1)$ \\
\hline
\end{tabular}

Figure 4. Structures of Natural flavonoids isolated from Erythrinawith their PTP1B inhibitory activities $\left(\mathrm{IC}_{50}\right.$ in $\left.\mu \mathrm{M}\right)$. * compound 23 is chromane derivative 


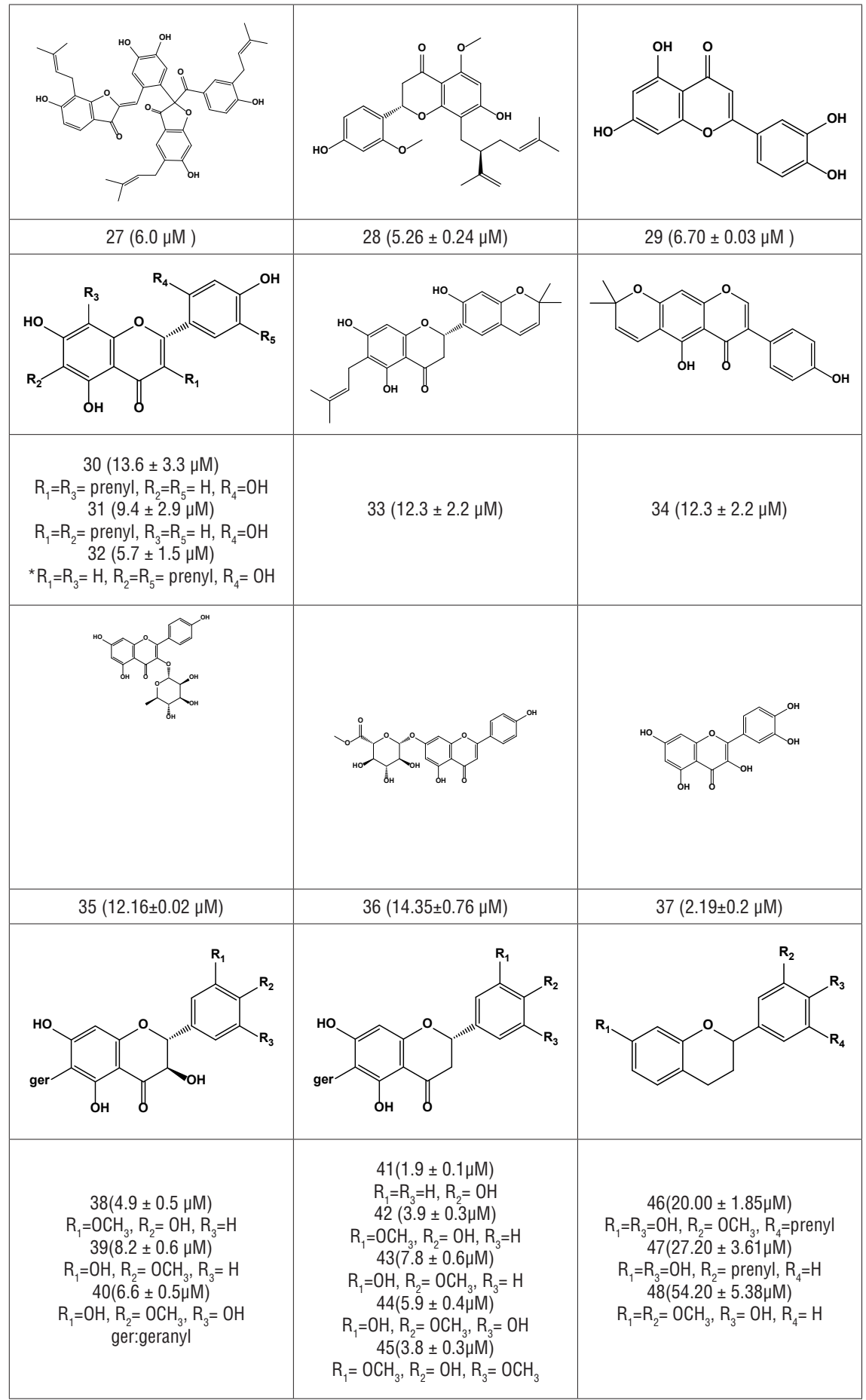




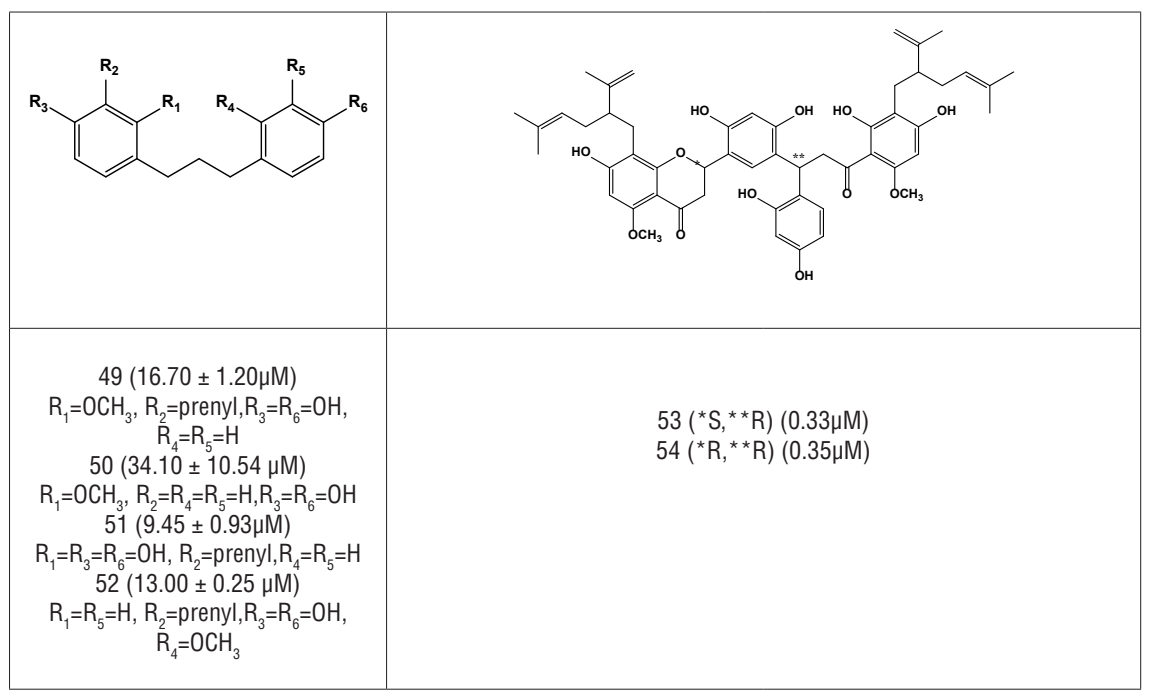

Figure 5: Chemical structure of natural PTP1B inhibitors. * compound 32 is chromane derivative

The aqueous extract of Broussonetia kazinoki has demonstrated a hypoglycemic effect in experimental diabetic rats ${ }^{42}$. Isoprenylatedflavan from B. kazinoki, Kazinol B, was effective in decreasing insulin resistance in $3 \mathrm{~T} 3$-L1 adipocytes via activation of AMPK and $\mathrm{PKB}^{43}$. According to the these results, it was proposed that $B$. kazinoki could be a potential source of compounds with antidiabetic activity. Interestingly, seven isolated compounds (46-52, Figure 5) exhibited in vitro $\mathrm{PTP} 1 \mathrm{~B}$ inhibitory activities with $\mathrm{IC}_{50}$ ranged between 9.45-54.20 $\mu \mathrm{M}^{44}$. The obtained results highlighted some points regarding the SAR of these natural compounds such as that compounds without prenyl group have weak or no activity, and glycosylation of the hydroxyl group decreases the activity.

Studying the ethanolic extract of Sophora flavescens resulted in the isolation of eight biflavonoids, consisting of a flavanone fused with a dihydrochalcone skeleton. Five of them were found to have potent in vitro PTP1B inhibitory activity (\%inhibition at $10 \mu \mathrm{M}$ was between 93.0-96.6\%) and the $\mathrm{IC}_{50}$ for two of them (53 and 54, Figure 5) was determined to be 0.33 and $0.35 \mu \mathrm{M}$, respectively ${ }^{45}$.

\section{Molecular modeling approaches in the discovery of flavonoids as PTP1B inhibitors}

The classical methods used in the discovery of new lead compounds and drugs are laborious, highly expensive, and time-consuming. A different surrogate strategy that could surmount such challenges is the utilization of computer- 
aided drug design (CADD). For example, molecular docking simulations were acknowledged as an effective method for predicting the interaction as well as binding energies of target-ligand complexes and therefore are very valuable in rational structure-based drug design. Recent advances in lead discovery from nature using cheminformatics and in silico screening is widely reported in the literature ${ }^{46-51}$.

Amentoflavone, a natural biflavonoid isolated from Selaginella tamariscina, was reported as PTP1B noncompetitive allosteric inhibitor $(K i=5.2 \mu \mathrm{M})^{52}$. Molecular docking simulations between PTP1B-allosteric site and amentoflavone were performed, and docking model was determined using AutoDock software. Depending on this docking model, multiple five featured-pharmacophore maps were generated: one lipophilic feature, two hydrogen bonding acceptors and two hydrogen bonding donors. Applying receptor-guided pharmacophorebased virtual screening against a database containing 40 natural biflavonoids resulted in the identification of two biflavonoids: sumaflavone (55) and tetrahydroamentoflavone (56) as potent allosteric inhibitors (Figure 6). Based on the docking results, it was proposed that the hydroxyl group at position 4' is significant factor for allosteric inhibition ${ }^{53}$.

A

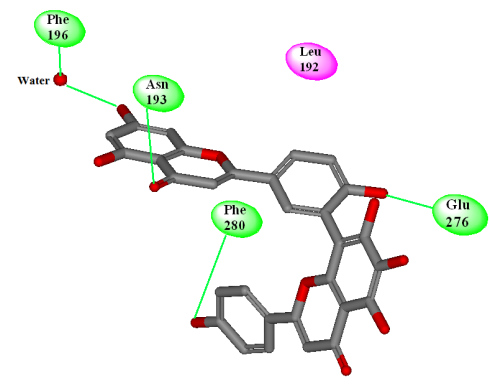

B

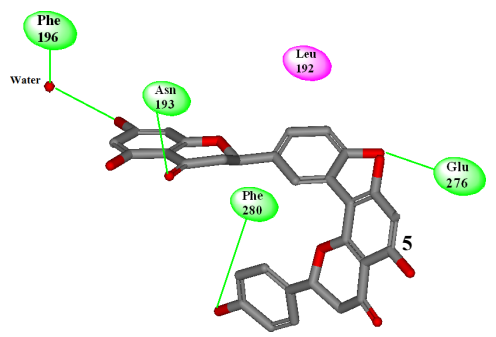

Figure 6: Docking models of biflavonoids and PTP1B. (A) Sumaflavone (55) (B) Tetrahydroamentoflavone $(56)^{53}$. Hydrogen bonds between protein and ligands are shown in green while hydrophobic contacts are represented in magenta. 
Screening of an in-house built database of 14 polyphenolic compounds against PTP1B revealed that morin and apigenin, two flavonoids widely abundant in herbs, vegetables, and fruits, are reversible PTP1B inhibitors ${ }^{54}$. Morin (57) was the most potent non-competitive PTP1B inhibitor $\left(\mathrm{IC}_{50}=15.0 \pm 0.8 ; K_{i}=5.9\right.$ $\pm 0.4 \mu \mathrm{M})$. In order to identify the binding mode of morin which could support a non-competitive mechanism of binding, it was docked with PTP1B using SwissDock. The docking model showed that morin doesn't bind in the catalytic pocket of PTP1B but fits in neighboring site forming 3 hydrogen bonds, with Gln262, Arg254, and Asp28, and hydrophobic interactions with Met258 and Gly259 with predicted binding energy $(\Delta \mathrm{G})=-6.827(\mathrm{kcal} / \mathrm{mol})$ (Figure 7).

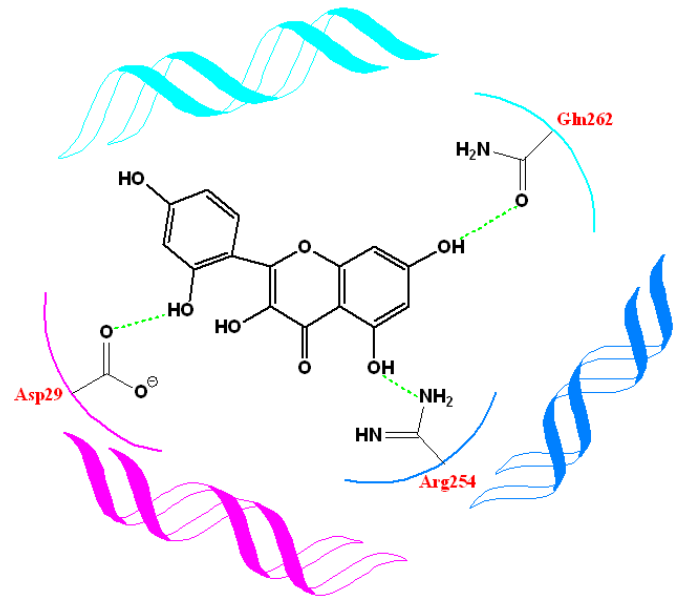

Figure 7: Graphical representation showing hydrogen bond network established by docked pose of Morin (57) and neighboring residues of PTP1B: Arg254, Gln262 and Asp29 (green lines) ${ }^{54}$.

In another study, the interactions between PTP1B with three noncompetitive flavonoid inhibitors, morin (57, MOR), 6,8-diprenylorobol (58, DPO), and 2'-methoxykurarinone (59, MOK) were explored. The three flavonoids were docked withinPTP1B allosteric site using Autodock software followed by molecular dynamics simulations, using GROMACS package, in order to investigate the conformational changes of PTP1B. Results showed that DPO (58) fits within the PTP1B site with the highest docking score i.e., estimated binding energy $=-8.3 \mathrm{kcal} / \mathrm{mol}\left(K_{i}=2.5\right.$ $\mu \mathrm{M})$. On the other hand, the predicted binding energies for MOK $\left(K_{i}=3.15 \mu \mathrm{M}\right)$ and MOR $\left(K_{i}=5.9 \mu \mathrm{M}\right)$ were -6.5 and $-5.3 \mathrm{kcal} / \mathrm{mol}$, respectively, which is in a direct correlation with their $K_{i}$ values (Figure 8) ${ }^{55}$. The dissimilarity in affinities of the 3 compounds was ascribed to non-bonded interactions and several hydrogen bonds using per-residue energy decomposition analysis. 


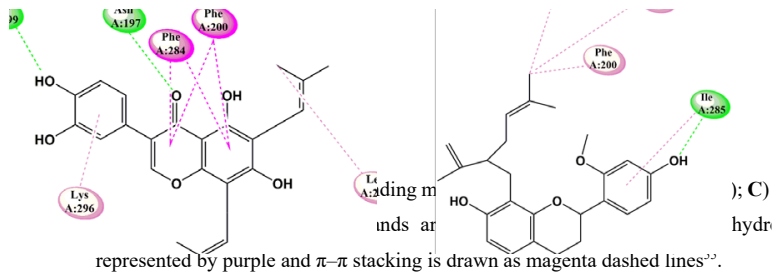

58

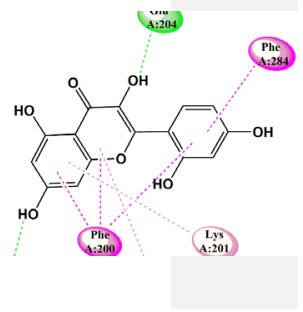

57

Figure 8. 2D representation of binding mode for: A) DPO (58); B) MOK (59); C) MOR (57). Hydrogen bonds between protein and ligands are drawn as green dashed lines, hydrophobic contacts are represented by purple and $\varpi-\varpi$ stacking is drawn as magenta dashed lines ${ }^{55}$.

A fractionation study conducted on the methanolic extract of rhubarb, Rheum undulatum L., resulted in the separation of 10 polyphenolic compounds including flavonoids. Three of them were stilbene derivatives (60-62) which exhibited significant PTP1B inhibition $\left(\mathrm{IC}_{50} \text { between } 4.25 \text { to } 6.78 \mu \mathrm{M}\right)^{56}$. Further investigations using docking simulations and kinetic analysis were conducted to reveal the binding mode and the potential interactions of PTP1B with the isolated stilbene derivatives. The obtained findings demonstrated noncompetitive PTP1B inhibition for (6o) and mixedtype inhibition for piceatannol (61) and $\delta$-viniferin (62). Further investigation for the active stilbenes using molecular docking showed a strong binding with key residues within the binding site PTP1B with relatively high negative energies (Figure 9).
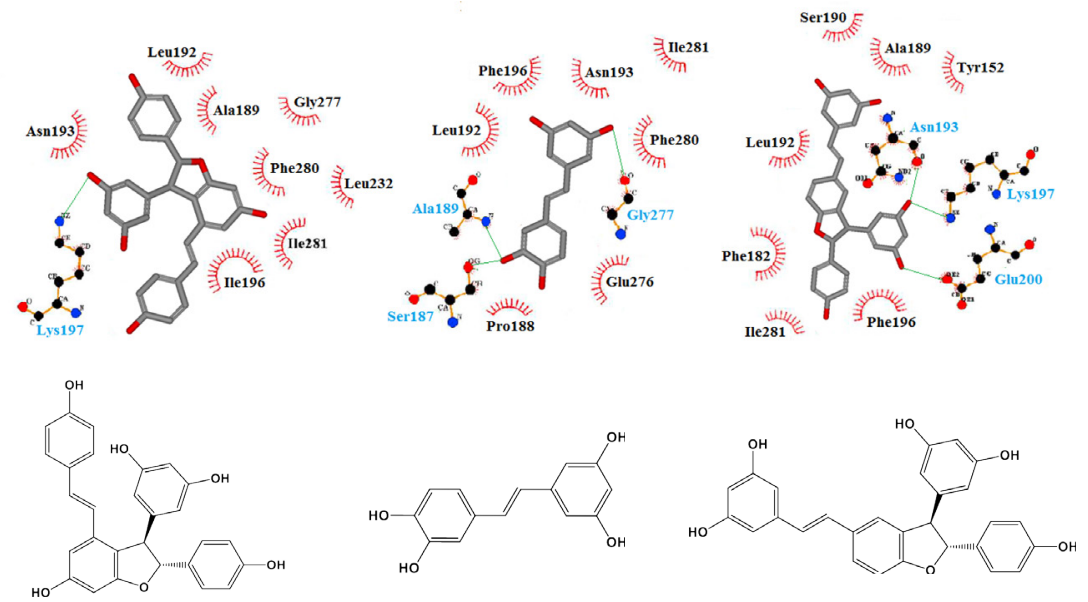

Figure 9: 2D ligand interaction diagram of $60(A), 61(B)$ and $62(C)$ in the allosteric site of PTP1B enzyme. Green lines indicate H-bonds. Carbons are in black, nitrogens in blue, and oxygens in red. Hydrogen bonds between protein and ligands are drawn as green lines ${ }^{56}$. 
Fifteen compounds, isolated from Anoectochilus chapaensis, were investigated for their PTP1B inhibitory activity in vitro ${ }^{57}$. Four flavonoids; quercetin (37), isorhamnetin, isorhamnetin-3-O- $\beta$-D-glucoside, isorhamnetin-3- $O-\beta-\mathrm{D}-$ rutinoside (63), showed significant $\mathrm{PTP} 1 \mathrm{~B}$ inhibition with $\mathrm{IC}_{50}$ values ranging from $1.16-5.63 \mu \mathrm{M}$. The results obtained by docking simulations revealed significant binding energies of -7.4 to $-7.8 \mathrm{kcal} / \mathrm{mol}$ indicating tight binding and supporting the high affinity to the active catalytic site of PTP1B. Among the tested flavonoids, compound $\mathbf{6 3}$ showed the highest PTP1B estimated binding energy $(-7.8 \mathrm{kcal} / \mathrm{mol})$. Thorough analysis of the estimated binding mode revealed that the stability of the PTP1B-inhibitors complex could be sustained by the formation of multiple hydrogen bonds within the active site (Figure10). Structure-activity relationship study of the flavonoid glycosides derivatives revealed that the carbohydrate moiety at $\mathrm{C}-3$ position has a great influence on PTP1B inhibitory activity ${ }^{57}$.

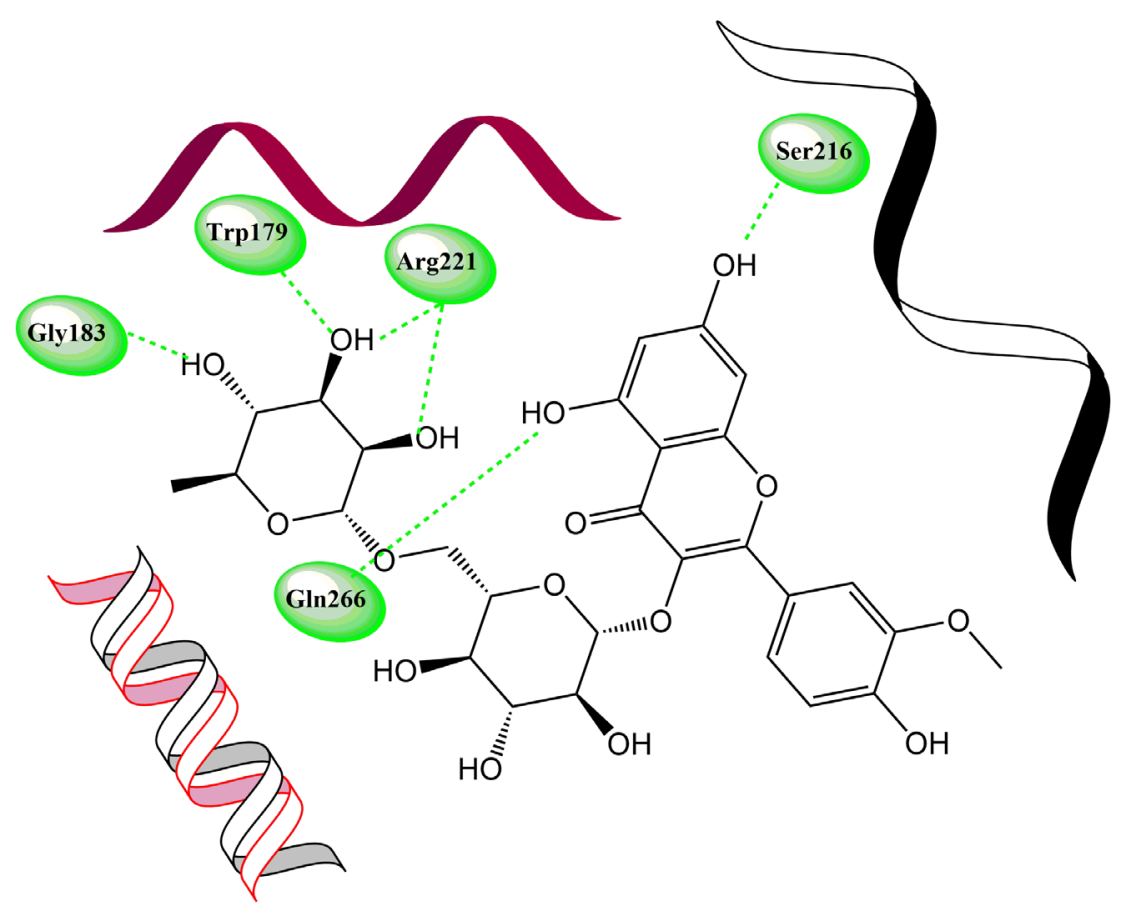

Figure 10: 2D ligand interaction diagram of binding mode of isorhamnetin-3-0- $\beta-D-$ rutinoside $\left(63, \mathrm{IC}_{50}=1.20 \pm 0.05 \mu \mathrm{M}\right)$ within PTP1B active site. Hydrogen bonds between protein and ligands are drawn as green dashed lines ${ }^{57}$. 
Furthermore, twenty-six phenolic natural products were extracted from the root bark of Morus alba. Ten compounds showed significant PTP1B inhibition with $\mathrm{IC}_{50}$ ranged between 1.90 and $9.67 \mu \mathrm{M}^{58}$. An enzymatic kinetic study showed that the three most potent compounds were noncompetitive allosteric PTP1B inhibitors, with $K_{i}$ values between 0.33-1.09 $\mu \mathrm{M}$. To investigate the binding modes and interaction of the most active compounds with PTP1B, docking simulations were conducted using AutoDock software. Docking results suggested that the three most potent compounds were noncompetitive allosteric inhibitors with negative binding energies range between -8.15 to -7.06 $\mathrm{kcal} / \mathrm{mol}$ which reflect their tight binding and high affinity for PTP1B. Figure 11 shows the docking results of two of the most potent compounds $(\mathbf{6 4}, \mathbf{6 5})$. As shown in figure 11 , both compounds shared the same $\pi-\pi$ stacked hydrophobic interaction with Phe196 and Phe28o. Interestingly, hydrogen bonding was observed between the hetero oxygen of the ketalized ring in compound (64) and the allosteric residue Asn193 but not with non-ketalized compound (65). This might partially explain why compound (64) has the highest PTP1B inhibitory activity and the lowest binding energy $(-8.15 \mathrm{kcal} / \mathrm{mol})$.
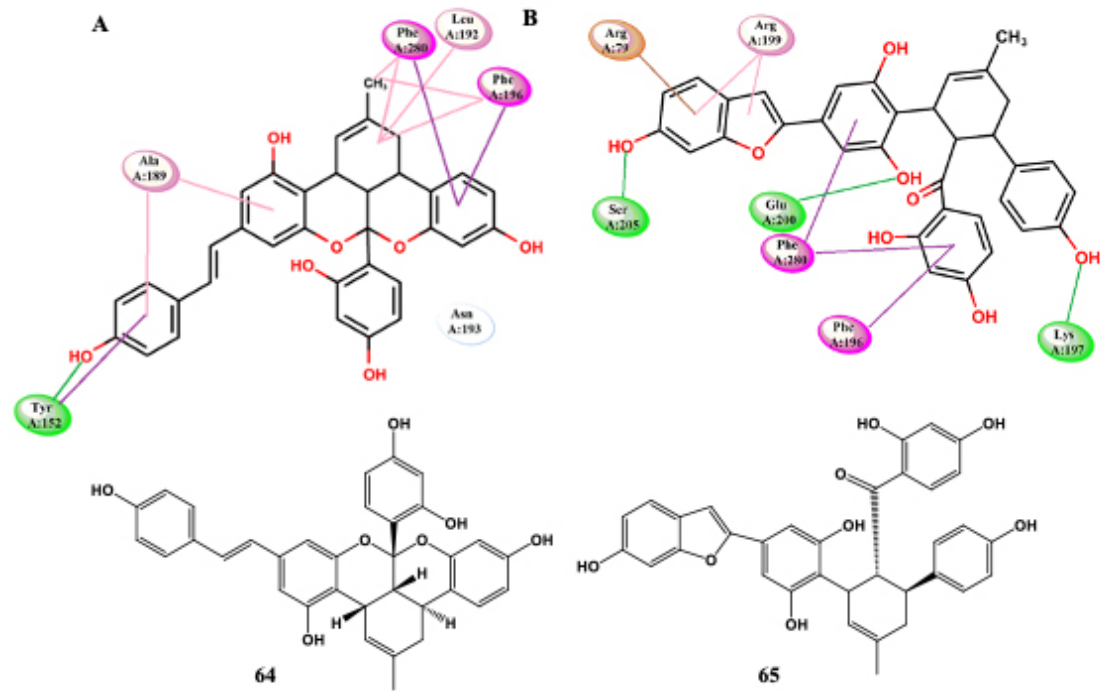

Figure 11: 2D diagram showing molecular docking results of PTP1B with: compound 64 $\left(\mathrm{IC}_{50}=1.90 \pm 0.12 \mu \mathrm{M}\right)(\mathrm{A})$ and compound $65\left(\mathrm{IC}_{50}=2.80 \pm 0.19 \mu \mathrm{M}\right)(\mathrm{B})$. Hydrogen bonds between protein and ligands are drawn as green lines, hydrophobic contacts are represented by purple, cation- $\pi$ interactions in brown and $\pi-\pi$ stacking in magenta ${ }^{58}$. 


\section{CONCLUSION}

Designing oral PTP1B inhibitors is a demanding task because of selectivity and bioavailability issues related to the homogeneity and the charged nature of the active site of PTP1B. Flavonoids have received much attention in the literature over the past decade, in which a variety of their potential therapeutic effects in several illnesses including diabetes, obesity, cancer, liver diseases, neurodegenerative diseases and cardiovascular diseases, have been verified. In fact, several natural flavonoids, acting as PTP1B inhibitors, have been proposed as potential antidiabetic drugs. These natural inhibitors, which possess interesting molecular architectures and potent activity, could be used as potential leads for developing promising drug candidates with better efficiency for the treatment of DM and its complications in the near future. This review focuses on summarizing the research efforts conducted in the discovery of flavonoids with PTP1B inhibitory activity, emphasizing the important role of molecular modeling and computer-aided drug design in the identification of these natural PTP1B inhibitors for the treatment of DM.

Unfortunately, despite the great efforts centered on the isolation and identification of many flavonoids as PTP1B inhibitors, and regardless of the diversity of the advanced molecular modeling techniques used in the discovery of these bioactive natural compounds, there were no further efforts exploited for optimization and development of these natural lead compounds into clinically effective drug candidates. Therefore, more research is required for the discovery and development of efficient flavonoids-based medicines with anti-PTP1B activity that could be used as antidiabetic drugs.

\section{CONFLICT OF INTESEST}

The authors do not have any conflict of interest. 


\section{REFERENCES}

1. Thomford NE, Senthebane DA, Rowe A, Munro D, Seele P, Maroyi A, et al. Natural Products for Drug Discovery in the 21st Century: Innovations for Novel Drug Discovery. Int J Mol Sci. 2018; 19(6): 1578. doi: 10.3390/ijms19061578.

2. Calixto JB. The role of natural products in modern drug discovery. An Acad Bras Ciênc. 2019; 91(Suppl. 3): e20190105. doi: 10.1590/0001-3765201920190105.

3. Park J, Jang H. Anti-diabetic effects of natural products an overview of therapeutic strategies. Mol Cell Toxicol. 2017; 13: 1-20. doi.org/10.1007/s13273-017-0001-1.

4. Vieira MN, Lyra E Silva NM, Ferreira ST, De Felice FG. Protein Tyrosine Phosphatase 1B (PTP1B): A Potential Target for Alzheimer's Therapy?. Front Aging Neurosci. 2017; 9:7. doi:10.3389/fnagi.2017.00007.

5. Song GJ, Jung M, Kim JH, Park H, Rahman MH, Zhang S, et al. A novel role for protein tyrosine phosphatase $1 \mathrm{~B}$ as a positive regulator of neuroinflammation. J Neuroinflammation, 2016; 13(1): 86. doi: 10.1186/s12974-016-0545-3.

6. Kostrzewa T, Styszko J, Gorska-Ponikowska M, Sledzinski T, Kuban-Jankowska A. Inhibitors of Protein Tyrosine Phosphatase PTP1B With Anticancer Potential. Anticancer Res. 2019; 39(7): 3379-3384. doi: 10.21873/anticanres.13481.

7. Kumar A, Rana D, Rana R, Bhatia R. Protein Tyrosine Phosphatase (PTP1B): A promising Drug Target Against Life-threatening Ailments. Curr Mol Pharmacol. 2020; 13(1): 17-30. doi: 10.2174/1874467212666190724150723.

8. Abdelsalam SS, Korashy HM, Zeidan A, Agouni A. The Role of Protein Tyrosine Phosphatase (PTP)-1B in Cardiovascular Disease and Its Interplay with Insulin Resistance. Biomolecules, 2019; 9(7): 286. doi: 10.3390/biom9070286.

9. Liu WS, Wang RR, Yue H, Zheng ZH, Lu XH, Wang SQ, et al. Design, synthesis, biological evaluation and molecular dynamics studies of 4-thiazolinone derivatives as protein tyrosine phosphatase 1B (PTP1B) inhibitors. J Biomol Struct Dyn. 2020; 38(13): 3814-3824. doi. org/10.1080/07391102.2019. 1664333 .

10. Jiang CS, Liang LF, Guo YW. Natural products possessing protein tyrosine phosphatase 1B (PTP1B) inhibitory activity found in the last decades. Acta Pharmacol Sin. 2012; 33(10): 12171245.doi: 10.1038/aps.2012.90.

11. Bhupathiraju SN, Hu FB. Epidemiology of Obesity and Diabetes and Their Cardiovascular Complications. Circ Res. 2016; 118(11): 1723-1735. doi: 10.1161/CIRCRESAHA.115.306825.

12. Xue W, Tian J, Wang XS, Xia J, Wu S. Discovery of potent PTP1B inhibitors via structurebased drug design, synthesis and in vitro bioassay of Norathyriol derivatives. Bioorg Chem. 2019; 86: 224-234. doi.org/10.1016/j.bioorg.2019.01.059.

13. Yeon JY, Bae YJ, Kim EY, Lee EJ. Association between flavonoid intake and diabetes risk among the Koreans. Clin Chim Acta. 2015; 439: 225-230.doi: 10.1016/j.cca.2014.10.042.

14. Bollu LR, Mazumdar A, Savage MI, Brown PH. Molecular Pathways: Targeting Protein Tyrosine Phosphatases in Cancer. Clin Cancer Res. 2017; 23(9): 2136-2142. doi: 10.1158/10780432.CCR-16-0934.

15. Johnson TO, Ermolieff J, Jirousek MR. Protein tyrosine phosphatase 1B inhibitors for diabetes. Nat Rev Drug Discov. 2oo2; 1(9): 696-709. doi.org/10.1038/nrd895. 
16. Tamrakar AK, Maurya CK, Rai AK. PTP1B inhibitors for type 2 diabetes treatment: a patent review (2011-2014). Expert Opin Ther Pat. 2014; 24(10): 1101-1115. doi: 10.1517/13543776.2014.947268.

17. Barford D, Flint AJ, Tonks NK. Crystal structure of human protein tyrosine phosphatase 1B. Science, 1994; 263(5152): 1397-404.

18. Shinde RN, Kumar GS, Eqbal S, Sobhia ME. Screening and identification of potential PTP1B allosteric inhibitors using in silico and in vitro approaches. PLoS One, 2018; 13(6): e0199020. doi: 10.1371/journal.pone.0199020.

19. Taha MO, Bustanji Y, Al-Bakri AG, Yousef AM, Zalloum WA, Al-Masri IM, et al. Discovery of new potent human protein tyrosine phosphatase inhibitors via pharmacophore and QSAR analysis followed by in silico screening. J Mol Graph Model. 2007; 25(6): 870-84. doi: 10.1016/j. jmgm.2006.08.008.

20. Sharma B, Xie L, Yang F, Wang W, Zhou Q, Xiang M, et al. Recent advance on PTP1B inhibitors and their biomedical applications. Eur J Med Chem. 2020; 199: 112376. doi.org/10.1016/j. ejmech.2020.112376.

21. Zargari F, Lotfi M, Shahraki O, Nikfarjam Z, Shahraki J. Flavonoids as potent allosteric inhibitors of protein tyrosine phosphatase 1B: molecular dynamics simulation and free energy calculation. J Biomol Struct Dyn. 2018; 36(15): 4126-4142. doi: 10.1080/07391102.2017.1409651.

22. Wiesmann C, Barr KJ, Kung J, Zhu J, Erlanson DA, Shen W, et al. Allosteric inhibition of protein tyrosine phosphatase 1B. Nat Struct Mol Biol. 2004; 11: 730-737. doi.org/10.1038/ nsmb803.

23. Krishnan N, Koveal D, Miller DH, Xue B, Akshinthala SD, Kragelj J, et al. Targeting the disordered C-terminus of PTP1B with an allosteric inhibitor. Nat Chem Biol. 2014; 10(7): 558566. doi.org/10.1038/nchembio.1528.

24. Proença C, Freitas M, Ribeiro D, Sousa JLC, Carvalho F, Silva AMS, et al. Inhibition of protein tyrosine phosphatase $1 \mathrm{~B}$ by flavonoids: A structure - activity relationship study. Food Chem Toxicol. 2018; 111: 474-481.doi: 10.1016/j.fct.2017.11.039.

25. Choi K, Kim YB. Molecular mechanism of insulin resistance in obesity and type 2 diabetes. Korean J Intern Med. 2010; 25(2): 119-129.doi:10.3904/kjim.2010.25.2.119.

26. Panche AN, Diwan AD, Chandra SR. Flavonoids: an overview. J Nutr Sci. 2016; 5: e47.doi: 10.1017/jns.2016.41.

27. Ueda K, Usui T, Nakayama H, Ueki M, Takio K. 4-Isoavenaciolide covalently binds and inhibits VHR, a dual-specificity phosphatase. FEBS Lett. 2oo2; 525: 48-52.doi: 10.1016/soo145793(02)03065-x.

28. Bae EY, Na M, Njamen D, Mbafor JT, Fomum ZT, Cui L, et al. Inhibition of protein tyrosine phosphatase $1 \mathrm{~B}$ by prenylated isoflavonoids isolated from the stem bark of Erythrina addisoniae. Planta Med. 2006; 72(10): 945-948.doi: 10.1055/s-2006-946674.

29. Na M, Hoang DM, Njamen D, Mbafor JT, Fomum ZT, Thuong PT, et al. Inhibitory effect of 2-arylbenzofurans from Erythrina addisoniae on protein tyrosine phosphatase-1B. Bioorg Med Chem Lett. 2007; 17(14): 3868-71.doi: 10.1016/j.bmcl.2007.05.005.

30. Cui L, Thuong PT, Lee HS, Ndinteh DT, Mbafor JT, Fomum ZT, et al. Flavanones from the stem bark of Erythrina abyssinica. Bioorg Med Chem. 2oo8; 16(24): 10356-62. doi. org/10.1016/j.bmc.2008.10.012. 
31. Nguyen PH, Le TV, Thuong PT, Dao TT, Ndinteh DT, Mbafor JT, et al. Cytotoxic and PTP1B inhibitory activities from Erythrina abyssinica. Bioorg Med Chem Lett. 2oo9; 19(23): 6745-9. doi: 10.1016/j.bmcl.2009.09.108.

32. Nguyen PH, Sharma G, Dao TT, Uddin MN, Kang KW, Ndinteh DT, at al. New prenylated isoflavonoids as protein tyrosine phosphatase $1 \mathrm{~B}(\mathrm{PTP} 1 \mathrm{~B})$ inhibitors from Erythrina addisoniae. Bioorg Med Chem. 2012; 20(21): 6459-64.doi: 10.1016/j.bmc.2012.08.024.

33. Dao TT, Nguyen PH, Thuong PT, Kang KW, Na M, Ndinteh DT, et al. Pterocarpans with inhibitory effects on protein tyrosine phosphatase 1B from Erythrina lysistemon Hutch. Phytochemistry, 2009; 70(17-18): 2053-7.doi: 10.1016/j.phytochem.2009.09.012.

34. Li W, Li S, Higai K, Sasaki T, Asada Y, Ohshima S, et al. Evaluation of licorice flavonoids as protein tyrosine phosphatase 1B inhibitors. Bioorg Med Chem Lett. 2013; 23(21): 5836-9.doi: 10.1016/j.bmcl.2013.08.102.

35. Sasaki T, Li W, Higai K, Quang TH, Kim YH, Koike K. Protein Tyrosine Phosphatase 1B Inhibitory Activity of Lavandulyl Flavonoids from Roots of Sophoraflavescens. Planta Med. 2014; 8o(7): 557-56o.doi: 10.1055/s-0034-1368400.

36. Choi JS, Islam MN, Ali MY, Kim YM, Park HJ, Sohn HS, et al. The effects of C-glycosylation of luteolin on its antioxidant, anti-Alzheimer's disease, anti-diabetic, and anti-inflammatory activities. Arch Pharm Res. 2014; 37(10): 1354-63.doi: 10.1007/s12272-014-0351-3.

37. Quang TH, Ngan NT, Yoon CS, Cho KH, Kang DG, Lee HS, et al. Protein Tyrosine Phosphatase 1B Inhibitors from the Roots of Cudraniatricuspidata. Molecules, 2015; 20(6):1117383.doi: 10.3390/molecules200611173.

38. Wu LQ, Lei C, Gao LX, Liao HB, Li JY, Li J, et al. Isoprenylated Flavonoids with PTP1B Inhibition from Ficus tikoua. Nat Prod Commun. 2015; 10(12): 2105-7.

39. Na B, Nguyen PH, Zhao BT, Vo QH, Min BS, Woo MH. Protein tyrosine phosphatase 1B (PTP1B) inhibitory activity and glucosidase inhibitory activity of compounds isolated from Agrimoniapilosa. Pharm Biol. 2016; 54(3): 474-80.doi: 10.3109/13880209.2015.1048372.

40. Jiang L, Numonov S, Bobakulov K, Qureshi MN, Zhao H, Aisa HA. Phytochemical profiling and evaluation of pharmacological activities of Hypericum scabrum L. Molecules, 2015; 20: 11257-11271.doi: 10.3390/molecules200611257.

41. Song YH, Uddin Z, Jin YM, Li Z, Curtis-Long MJ, Kim KD, et al. Inhibition of protein tyrosine phosphatase (PTP1B) and $\alpha$-glucosidase by geranylated flavonoids from Paulownia tomentosa. J Enzyme Inhib Med Chem. 2017; 32(1): 1195-1202.doi: 10.1080/14756366.2017.1368502.

42. Cha JY, Kim YT, Kim HS, Cho YS. Antihyperglycemic effect of stem bark powder from paper mulberry (Broussonetia kazinoki Sieb.) in type 2 diabetic Otsuka Long-Evans Tokushima fatty rats. J Med Food, 2008; 11(3): 499-505.doi: 10.1089/jmf.2007.0028.

43. Lee H, Li H, Jeong JH, Noh M, Ryu JH. Kazinol B from Broussonetiakazinoki improves insulin sensitivity via Akt and AMPK activation in 3T3-L1 adipocytes. Fitoterapia, 2016; 112: 90-96.doi: 10.1016/j.fitote.2016.05.006.

44. Xue JJ, Lei C, Wang PP, Kim KY, Li JY, Li J, et al. Flavans and diphenylpropanes with PTP1B inhibition from Broussonetia kazinoki. Fitoterapia, 2018; 130: 37-42. https://doi. org/10.1016/j.fitote.2018.08.001.

45. Yan HW, Zhu H, Yuan X, Yang Y-N, Feng Z-M, Jiang J-S, et al. Eight new biflavonoids with lavandulyl units from the roots of Sophoraflavescens and their inhibitory effect on PTP1B. 
Bioorg Chem. 2019; 86: 679-685.doi: 10.1016/j.bioorg.2019.01.058.

46. Mohammad M, Almasri I, Issa A, Khdair A, Bustanji Y. Inhibition of pancreatic lipase by berberine and dihydroberberine: an investigation by docking simulation and experimental validation. Med Chem Res. 2013; 22: 2273-2278. doi.org/10.1007/s00044-012-0221-9.

47. Abu-Gharbieh E, Shehab NG, Almasri IM, Bustanji Y. Antihyperuricemic and xanthine oxidase inhibitory activities of Tribulusarabicus and its isolated compound, ursolic acid: In vitro and in vivo investigation and docking simulations. PLoS One, 2018; 13(8): e0202572. doi: 10.1371/journal.pone.0202572.

48. Almasri IM. Computational approaches for the discovery of natural pancreatic lipase inhibitors as antiobesity agents. Future Med Chem. 2020; 12(8): 741-757.doi: 10.4155/fmc-20190284 .

49. Bustanji Y, Taha MO, Yousef AM, Al-Bakri AG. Berberine potently inhibits protein tyrosine phosphatase 1B: investigation by docking simulation and experimental validation. $J$ Enzyme Inhib Med Chem. 20o6; 21(2): 163-71.doi: 10.1080/14756360500533026.

50. Bustanji Y, Taha MO, Almasri IM, Mohammad MK. Docking simulations and in vitro assay unveil potent inhibitory action of papaverine against protein tyrosine phosphatase $1 \mathrm{~B}$. Biol Pharm Bull. 2009; 32(4): 640-5.doi: 10.1248/bpb.32.640.

51. Harb A, Bustanji Y, Almasri I, Abdalla SS. Eugenol Reduces LDL Cholesterol and Hepatic Steatosis in Hypercholesterolemic Rats by Modulating TRPV1 Receptor. Sci Rep. 2019; 9:14003. https://doi.org/10.1038/s41598-019-50352-4.

52. Na M, Kim KA, Oh H, Kim BY, Oh WK, Ahn JS. Protein tyrosine phosphatase 1B inhibitory activity of amentoflavone and its cellular effect on tyrosine phosphorylation of insulin receptors. Biol Pharm Bull. 2007; 30(2): 379-381.doi: 10.1248/bpb.30.379.

53. Lee JY, Jeong KW, Woo ER, Kim Y. Docking Study of Biflavonoids, Allosteric Inhibitors of Protein Tyrosine Phosphatase 1B. Bull Korean Chem Soc. 2oo8; 29(8): 1479-1484. doi: 10.5012/bkcs.2008.29.8.1479.

54. Paoli P, Cirri P, Caselli A, Ranaldi F, Bruschi G, Santi A, et al. The insulin-mimetic effect of Morin: a promising molecule in diabetes treatment. BiochimBiophys Acta. 2013; 1830(4): 3102-11.doi: 10.1016/j.bbagen.2013.01.017.

55. Zargari F, Lotfi M, Shahraki O, Nikfarjam Z, Shahraki J. Flavonoids as potent allosteric inhibitors of protein tyrosine phosphatase 1B: molecular dynamics simulation and free energy calculation. J Biomol Struct Dyn. 2018; 36(15): 4126-4142. doi: 10.1080/07391102.2017.1409651.

56. Ha MT, Park DH, Shrestha S, Kim M, Kim JA, Woo MH, et al. PTP1B inhibitory activity and molecular docking analysis of stilbene derivatives from the rhizomes of Rheum undulatum L. Fitoterapia, 2018; 131: 119-126. https://doi.org/10.1016/j.fitote.2018.10.020

57. Cai J, Zhao L, Tao W. Potent protein tyrosine phosphatase 1B (PTP1B) inhibiting constituents from Anoectochiluschapaensis and molecular docking studies. Pharm Biol. 2015; 53(7): 1030-4.doi: 10.3109/13880209.2014.957781.

58. Ha MT, Seong SH, Nguyen TD, Choe W-K, Ah KJ, Mae JY, et al. Chalcone derivatives from the root bark of Morusalba L. act as inhibitors of PTP1B and a-glucosidase. Phytochemistry, 2018; 155: 114-125.doi:10.1016/j.phytochem.2018.08.001. 